Article

\title{
Cobalt Oxide Nanosheet and CNT Micro Carbon Monoxide Sensor Integrated with Readout Circuit on Chip
}

\section{Ching-Liang Dai ${ }^{1}{ }^{1}$, Yen-Chi Chen ${ }^{1}$, Chyan-Chyi $\mathrm{Wu}^{2}{ }^{2}$ and Chin-Fu Kuo ${ }^{3}$}

1 Department of Mechanical Engineering, National Chung Hsing University, Taichung, 402 Taiwan; E-Mail: metallica0515@msn.com (Y.-C.C.)

2 Department of Mechanical and Electro-Mechanical Engineering, Tamkang University, Tamsui, 251 Taiwan; E-Mail: ccwu@mail.tku.edu.tw (C.-C.W.)

3 Microsystems Technology Center, Industrial Technology Research Institute, Tainan, 709 Taiwan; E-Mail: kuochinfu@itri.org.tw (C.-F.K.)

* Author to whom correspondence should be addressed; E-Mail: cldai@dragon.nchu.edu.tw; Tel.: +886-4-22840433; Fax: +886-4-22877170.

Received: 31 December 2009; in revised form: 30 January 2010 / Accepted: 4 February 2010 / Published: 3 March 2010

\begin{abstract}
The study presents a micro carbon monoxide (CO) sensor integrated with a readout circuit-on-a-chip manufactured by the commercial $0.35 \mu \mathrm{m}$ complementary metal oxide semiconductor (CMOS) process and a post-process. The sensing film of the sensor is a composite cobalt oxide nanosheet and carbon nanotube $(\mathrm{CoOOH} / \mathrm{CNT})$ film that is prepared by a precipitation-oxidation method. The structure of the $\mathrm{CO}$ sensor is composed of a polysilicon resistor and a sensing film. The sensor, which is of a resistive type, changes its resistance when the sensing film adsorbs or desorbs CO gas. The readout circuit is used to convert the sensor resistance into the voltage output. The post-processing of the sensor includes etching the sacrificial layers and coating the sensing film. The advantages of the sensor include room temperature operation, short response/recovery times and easy post-processing. Experimental results show that the sensitivity of the CO sensor is about $0.19 \mathrm{mV} / \mathrm{ppm}$, and the response and recovery times are $23 \mathrm{~s}$ and $34 \mathrm{~s}$ for 200 ppm CO, respectively.
\end{abstract}

Keywords: micro carbon monoxide sensor; cobalt oxide film; readout circuit 


\section{Introduction}

Carbon monoxide sensors are widely applied in industrial and environmental monitoring. The sensitivity of gas sensors depends on the material of their sensing films. Several materials, such as $\mathrm{SnO}_{2}, \mathrm{ZnO}, \mathrm{ZnO}-\mathrm{CuO}, \mathrm{In}_{2} \mathrm{O}_{3}$ and $\mathrm{WO}_{3}-\mathrm{In}_{2} \mathrm{O}_{3}$ [1-5], have been utilized as $\mathrm{CO}$ gas sensing films. However, the above-mentioned films share as a common weakness that the working temperature is too high, leading to increased power consumption. Cobalt oxide can sense CO gas at room temperature [6]. Wu et al. [7] manufactured a $\mathrm{CO}$ sensor based on the sensing material $\mathrm{CoOOH}-\mathrm{WO}_{3}$ with single wall CNTs. The role of the added CNTs was to act as a conducting wire and increase the electric conductivity of the sensing film, resulting in shortened response and recovery times for the sensor. Consequently, in this study cobalt oxide with CNTs was adopted as a CO sensing material.

Several micro devices have been manufactured using microelectromechanical system (MEMS) technology [8]. Micro gas sensors fabricated by MEMS technology have the advantages of small size, high performance, low cost and easy mass-production. Many studies have used MEMS technology to develop micro carbon monoxide sensors. For instance, Tabata et al. [9] proposed a micro CO sensor manufactured using a silicon micromachining technique; its structure consisted of a catalytic thick film $/ \mathrm{SnO}_{2}$ thin film bilayer and a thin film heater. The thin film heater and the $\mathrm{SnO}_{2}$ thin film sensing layer were deposited on a silicon oxide-silicon nitride membrane. Chan et al. [10] reported a gas sensor with a micro hotplate for CO sensing, and the thermally isolated hotplate was fabricated using a surface silicon micromachining technique. Barrettino et al. [11] fabricated a microsystem for gas detection using the industrial $0.8 \mu \mathrm{m}$ CMOS technology combined with post-CMOS micromachining. The microsystem comprised an array of three micro hotplates, and three single-ended temperature controllers were used to regulate the micro hotplate temperature up to $350^{\circ} \mathrm{C}$. The micro hotplates were covered with tin dioxide for $\mathrm{CO}$ gas sensing. Briand et al. [12] presented a gas sensor with micromachined hotplates for $\mathrm{CO}$ gas sensing applications. The sensor was coated with a Pd-doped tin oxide drop and annealed using the integrated heater. These CO sensors [9-12] did not have integrated circuits-on-a-chip, so they needed to couple with circuits by packaging, leading to an increase in package cost. Integrating gas sensors with circuits-on-a-chip helps to reduce the packaging cost and enhance the performance. Thereby, in this work a carbon monoxide sensor integrated with a readout circuit-on-a-chip was developed. The readout circuit is an instrumentation amplifier circuitry [13] that can convert the sensor resistance into an output voltage.

The manufacturing technique which uses the commercial CMOS process to fabricate MEMS devices is called CMOS-MEMS [14-16]. Micro devices made by the CMOS-MEMS technique usually need a post-process to coat the functional films [17] or to release the suspended structures [18]. For example, Liu et al. [17] coated a sensitive film of polyaniline nanofiber on a micro ammonia sensor using a post-process. The benefits of CMOS-MEMS micro devices include integration with integrated circuits-on-a-chip, low cost per unit area and easy mass-production utilizing semiconductor foundries. In this study, the CMOS-MEMS technique was employed to fabricate a micro carbon monoxide sensor integrated with a readout circuit-on-a-chip. The sensing film of the sensor is a composite cobalt oxide nanosheet and carbon nanotube film, which was synthesized by a precipitation-oxidation method. The method needs to add a precipitant and an oxidant into the synthesized material. For instance, Wu et al. [19] used a precipitation-oxidation method to prepare a cobalt oxide film that was made from 
a $\mathrm{Co}\left(\mathrm{NO}_{3}\right)_{2}$ solution via precipitation with $\mathrm{NaOH}$ and oxidation in air. The carbon monoxide sensor needs post-processing to coat the sensing film. The post-process employed etchants to etch the sacrificial layers, and then the sensing film is coated on the sensor. When the sensing film adsorbs or desorbs $\mathrm{CO}$ gas, the sensor generates a change in resistance. The resistance of the sensor was converted by the readout circuit into the voltage output.

\section{Preparation of the CO Sensing Film}

The CO sensing film, a composite film of cobalt oxide and carbon nanotubes, was synthesized by the precipitation-oxidation method [20]. In the procedure, $1.5 \mathrm{~g}$ cobaltous nitrate [ $\mathrm{Co}\left(\mathrm{NO}_{3}\right)_{2} \cdot 6 \mathrm{H}_{2} \mathrm{O}$ ] was dissolved in $50 \mathrm{~mL}$ DI water with vigorous stirring. Next, aqueous sodium hydroxide $(\mathrm{NaOH})$ solution $(5 \mathrm{M}, 100 \mathrm{~mL})$ was added drop-wise to the above solution under constant stirring until the $\mathrm{pH}$ of the suspension increased to 12 , then $1 \mathrm{~mL}$ of CNT solution was added to the mixed solution, as shown in Table 1. Then, the flask was sealed and heated at $80^{\circ} \mathrm{C}$ for $24 \mathrm{~h}$. After the reaction was completed, the solution needed to cool to room temperature naturally. The precipitate was washed with DI water and ethanol. Finally, the film was coated on the silicon substrate, followed by calcination in air at $120^{\circ} \mathrm{C}$ for $2 \mathrm{~h}$.

Figure 1. SEM images of the $\mathrm{CoOOH} / \mathrm{CNT}$ film; (a) low magnification; (b) high magnification.
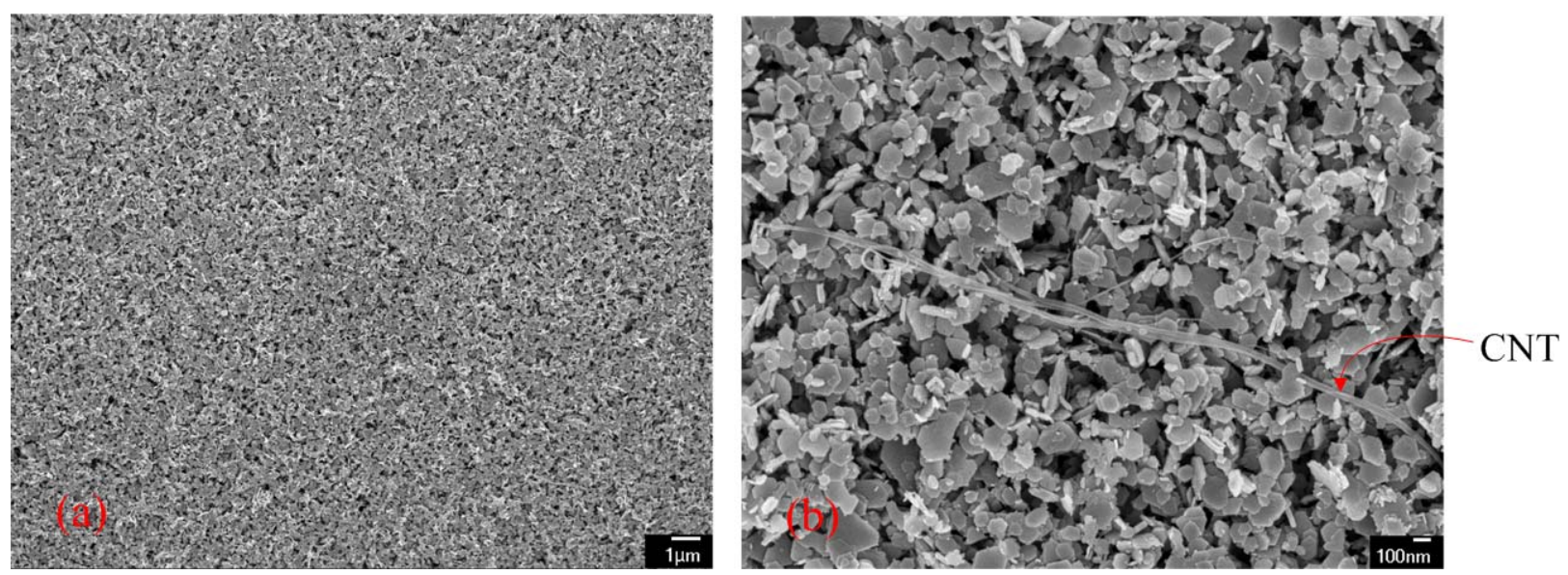

Table 1. Composition of the CNT solution.

\begin{tabular}{cc}
\hline Material & Weight \% \\
\hline Sodium dodecyl sulfate & 1 \\
CNT & 9 \\
DI water & 90 \\
Totals & 100 \\
\hline
\end{tabular}

The surface morphology of the CoOOH/CNT film was examined by scanning electron microscopy (SEM) (JEOL JSM-6700F). Figures 1(a) and (b) show the low- and high-magnification scanning electron microscopy images of the $\mathrm{CoOOH} / \mathrm{CNT}$ film after the synthesis. Figure 1(a) shows that the film has a porous structure. Figure 1(b) indicates that the film consists of a $\mathrm{CoOOH}$ nanosheet and CNTs. The elements of the $\mathrm{CoOOH} / \mathrm{CNT}$ film were measured by an energy dispersive spectrometer 
(OXFORD INCA ENERGY 400), and the measured results are shown in Figure 2. The CoOOH/CNT film contained $43.5 \mathrm{wt} \% \mathrm{Co}, 42.8 \mathrm{wt} \% \mathrm{O}, 6.9 \mathrm{wt} \% \mathrm{C}, 5.5 \mathrm{wt} \% \mathrm{Na}$ and $1.3 \mathrm{wt} \% \mathrm{~S}$. The composition of the film is summarized in Table 2. The main components of the film were cobalt and oxygen. The element $\mathrm{Na}$ resulted from the precipitant of $\mathrm{NaOH}$, and the element $\mathrm{S}$ was generated by the dispersant of sodium dodecyl sulfate in the CNT solution. The influence of these elements on the sensing film was assumed to be negligible dues to the very small amounts present.

Figure 2. Elements of CoOOH/CNT film measured by energy dispersive spectrometer

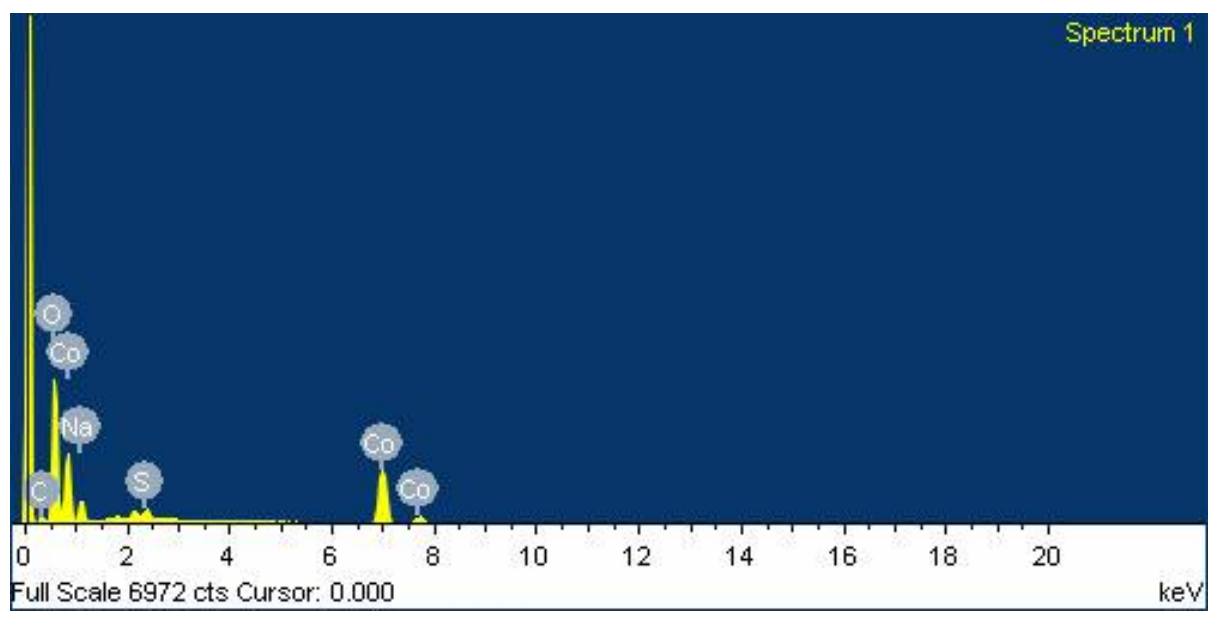

Table 2. Composition of CoOOH/CNT film.

\begin{tabular}{cc}
\hline Element & Weight $\%$ \\
\hline Co & 43.5 \\
$\mathrm{O}$ & 42.8 \\
$\mathrm{C}$ & 6.9 \\
$\mathrm{Na}$ & 5.5 \\
$\mathrm{~S}$ & 1.3 \\
Total: & 100 \\
\hline
\end{tabular}

\section{Structure of the CO Sensor}

Figure 3 illustrates the structure of the integrated chip that contains a $\mathrm{CO}$ sensor and a readout circuit. The area of the CO sensor is about $1 \mathrm{~mm}^{2}$. The CO sensor consists of a polysilicon resistor and a CO sensing film. A silicon dioxide layer is located between the polysilicon resistor and the sensing film. As shown in Figure 3, the polysilicon resistor is connected to the readout circuit. The $\mathrm{CoOOH} / \mathrm{CNTs} \mathrm{CO}$ sensing film is coated on the polysilicon resistor. The polysilicon resistor is $2 \mu \mathrm{m}$ wide, $0.4 \mu \mathrm{m}$ thick and $11,000 \mu \mathrm{m}$ long. When the sensing film of the sensor absorbs or desorbs $\mathrm{CO}$ gas, its energy band produces a change, resulting in changes to the energy band of the polysilicon resistor [21]. The polysilicon resistor generates a change in resistance as its energy band varies. The resistance variation of the $\mathrm{CO}$ sensor is converted by the readout circuit into the voltage output. 
Figure 3. Schematic structure of the CO sensor with the readout circuit.

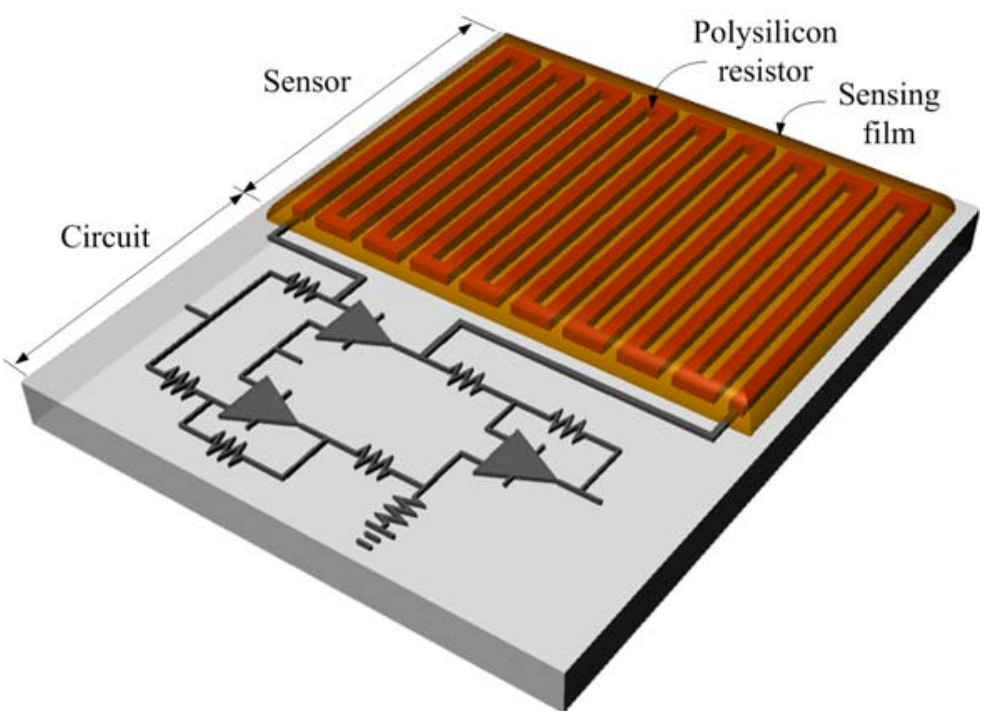

Figure 4. Energy band diagram of the $\mathrm{CO}$ sensor. $\mathrm{E}_{\mathrm{F}}$ is the Fermi level, $\mathrm{E}_{\mathrm{c}-\mathrm{CoOOH}}$ is the conduction band of $\mathrm{CoOOH}, \mathrm{E}_{\mathrm{v}-\mathrm{CoOOH}}$ is the valence band of $\mathrm{CoOOH}, \mathrm{E}_{\mathrm{Fi}-\mathrm{CoOOH}}$ is the intrinsic Fermi level of $\mathrm{CoOOH}, \mathrm{E}_{\mathrm{c}-\text { poly }}$ is the conduction band of polysilicon, $\mathrm{E}_{\mathrm{v} \text {-poly }}$ is the valence band of polysilicon, $\mathrm{E}_{\mathrm{Fi} \text {-poly }}$ is the intrinsic Fermi of polysilicon, $q$ is the electronic charge, $\phi_{s}$ is negative surface potential and $V_{s}$ is the potential barrier.

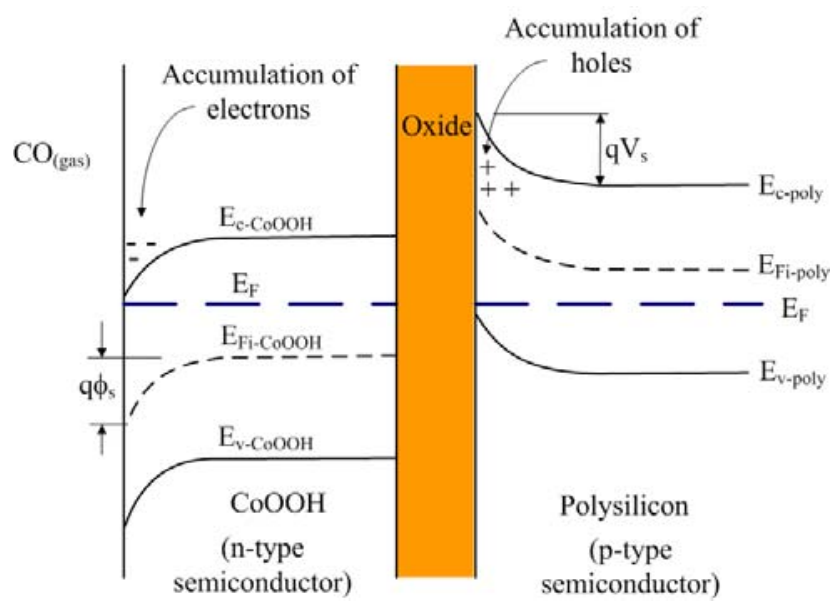

The $\mathrm{CO}$ sensing mechanism on $\mathrm{CoOOH}$ has been reported to take the form of gas-phase $\mathrm{CO}$ adsorption and desorption on cobalt sites, and reaction of the adsorbed $\mathrm{CO}$ with lattice oxygen atoms to form $\mathrm{CO}_{2}$ [19]. Equation (1) represents the adsorption and desorption of $\mathrm{CO}$ and Equation (2) shows the surface reaction of $\mathrm{CO}$ and $\mathrm{O}_{2}$ :

$$
\begin{aligned}
& \mathrm{CO}+*+\mathrm{e}^{-} \leftrightarrow \mathrm{CO}-*^{-} \\
& \mathrm{CO}-*^{-}+\mathrm{O}-* \rightarrow \mathrm{CO}_{2}+2 *+\mathrm{e}^{-}
\end{aligned}
$$

where * represents the active sensing vacant sites on the surface and $\mathrm{CO}-*^{-}$is the absorbed $\mathrm{CO}$ on the surface. Figure 4 illustrates the energy band diagram of the $\mathrm{CO}$ sensor. The cobalt oxide is an n-type semiconductor, and the polysilicon is p-type. When the surface of $\mathrm{CoOOH}$ is exposed to $\mathrm{CO}$ gas, 
electrons are produced at the surface of $\mathrm{CoOOH}$ according to Equation (2). As shown in Figure 4, an accumulation of electrons is formed at the surface of $\mathrm{CoOOH}$ when $\mathrm{CO}$ gas interacts with $\mathrm{CoOOH}$, so that the conduction and valence band edges of $\mathrm{CoOOH}$ bend downward, resulting in generation of a negative surface potential, $\phi_{s}$. An accumulation of holes at the oxide-polysilicon interface is formed by the negative surface potential $\phi_{s}$, which leads to the conduction and valence band edges of polysilicon to bend upward and causes the production of the potential barrier, $V_{s}$ [21]. When the CoOOH film of the $\mathrm{CO}$ sensor is in a high $\mathrm{CO}$ environment, the surface potential $\phi_{s}$ increases, resulting in an increase of the potential barrier $V_{s}$ and a decrease of the polysilicon resistance. Therefore, the resistance of polysilicon increases as the amount of $\mathrm{CO}$ sensed by the $\mathrm{CoOOH}$ increases.

Figure 5 illustrates the readout circuit for the CO sensor, where $R_{s}$ represents the resistance of the sensor; $V_{d d}$ is the bias voltage of the circuit; $V_{s s}$ is the ground; $V_{i n 1}$ and $V_{i n 2}$ are the input voltages of the circuit and $V_{\text {out }}$ is the output voltage of the circuit. The readout circuit contains three amplifiers, where $O P 1$ and OP2 are non-inverting amplifiers; OP3 is a difference amplifier. The resistance of the sensor changes as the sensing film adsorbs or desorbs $\mathrm{CO}$ gas. The readout circuit is employed to convert the resistance of the $C O$ sensor into the voltage output. In this design, $R_{1}=1 \mathrm{k} \Omega, R_{2}=1 \mathrm{k} \Omega, R_{3}=10 \mathrm{k} \Omega$, $R_{4}=100 \Omega, R_{5}=100 \Omega, R_{6}=15 \mathrm{k} \Omega$ and $R_{7}=20 \mathrm{k} \Omega$ are adopted. HSPICE, which is a professional circuit simulation software, is utilized to simulate the characteristics of the readout circuit.

Figure 5. Readout circuit for the CO sensor.

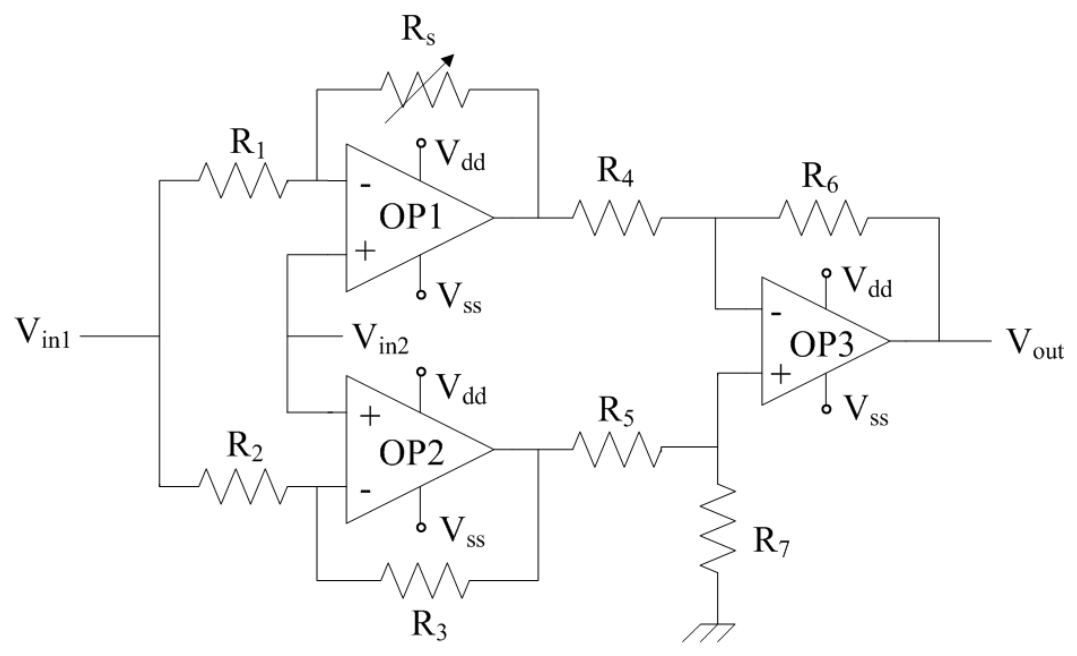

Figure 6 shows the relation between the input voltage $V_{\text {in } 1}$ and the output voltage $V_{\text {out }}$ for the readout circuit. In this simulation, the resistance $R_{s}$ of the sensor is set as $20 \mathrm{k} \Omega$. The bias voltage $V_{d d}$ is $3.3 \mathrm{~V}$ and the input voltage $V_{\text {in } 2}$ is $3 \mathrm{~V}$. The simulated results depict that the output voltages of the readout circuit are 300,570 and $850 \mathrm{mV}$ when the input voltages $V_{i n 1}$ are 1, 2 and $3 \mathrm{~V}$, respectively. The input voltage of the readout circuit increases, then its output voltage becomes large. 
Figure 6. Relation between the output and input voltages for the readout circuit.

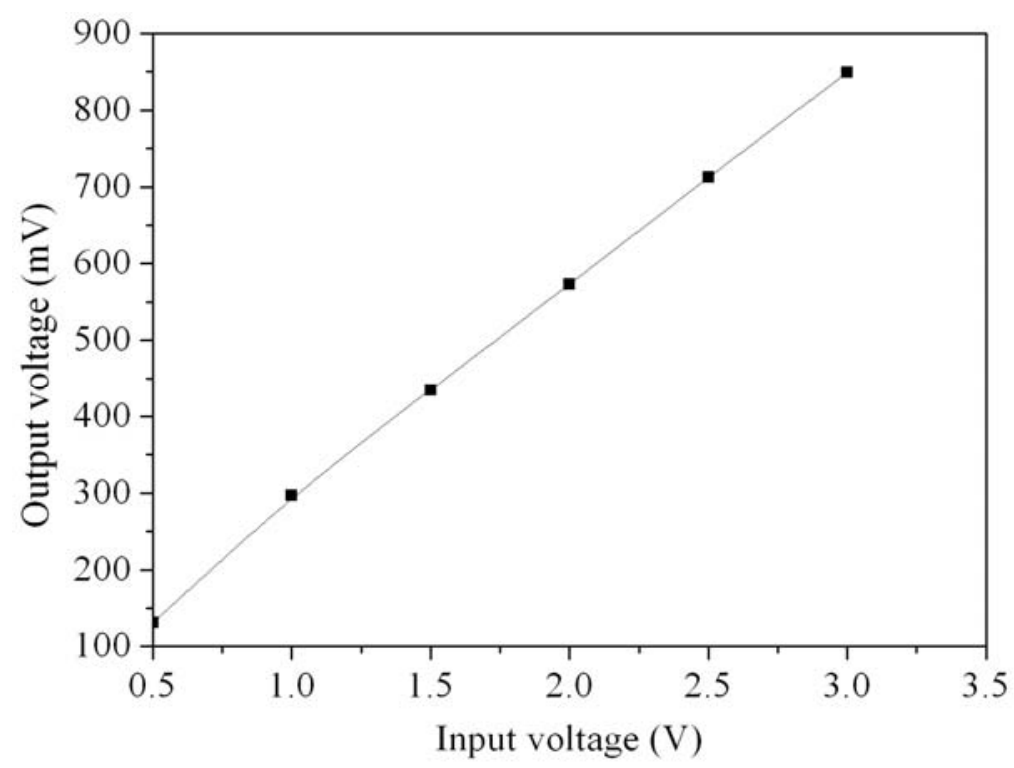

Figure 7 presents the relation between the output voltage of readout circuit and the resistance of sensor. In this investigation, the input voltages $V_{i n 1}$ and $V_{\text {in2 }}$ are $3 \mathrm{~V}$, the resistance of the sensor changes from 20 to $21.2 \mathrm{k} \Omega$. The output voltage of the readout circuit changes from 850 to $890 \mathrm{mV}$ as the resistance of the sensor varies from 20 to $21.2 \mathrm{k} \Omega$.

Figure 7. Simulated results of the output voltage for the CO sensor.

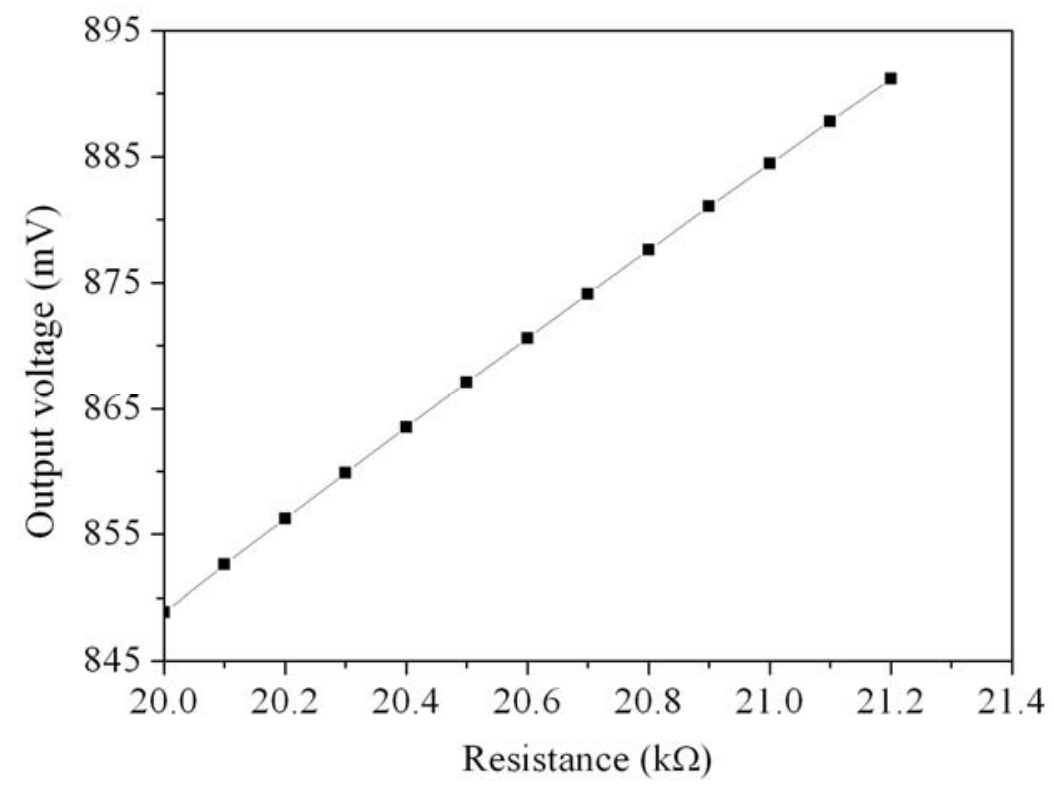

\section{Fabrication of the CO Sensor}

The micro $\mathrm{CO}$ sensor integrated with a readout circuit-on-a-chip was fabricated using the commercial $0.35 \mu \mathrm{m}$ CMOS process of the Taiwan Semiconductor Manufacturing Company (TSMC). After completion of the CMOS process, the CO sensor chip needs a post-process to expose the polysilicon resistor and coat the $\mathrm{CO}$ sensing film. The post-process consisted of two main steps: (1) the sacrificial layers were etched to expose the polysilicon resistor; (2) the CO sensing film was coated on 
the polysilicon resistor. Figure 8 illustrates the fabrication process of the $\mathrm{CO}$ sensor chip. Figure 8(a) presents the cross-section of the $\mathrm{CO}$ sensor chip after completion of the CMOS process. Figure 9 depicts a photograph of the $\mathrm{CO}$ sensor with its readout circuit after the CMOS process.

Figure 8. Fabrication process of the $\mathrm{CO}$ sensor: (a) after the CMOS process, (b) etching the sacrificial layer, (c) coating the sensing film.
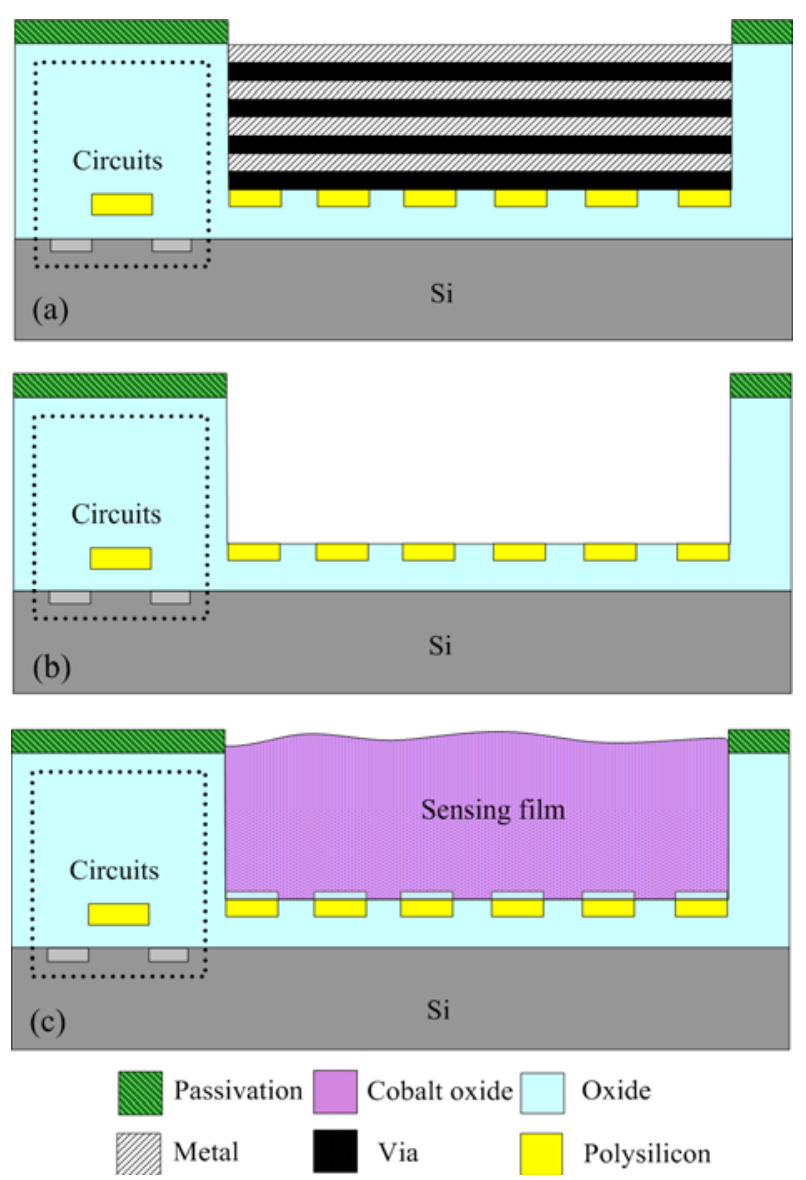

Figure 9. Photographic image of the CO sensor after the CMOS process.

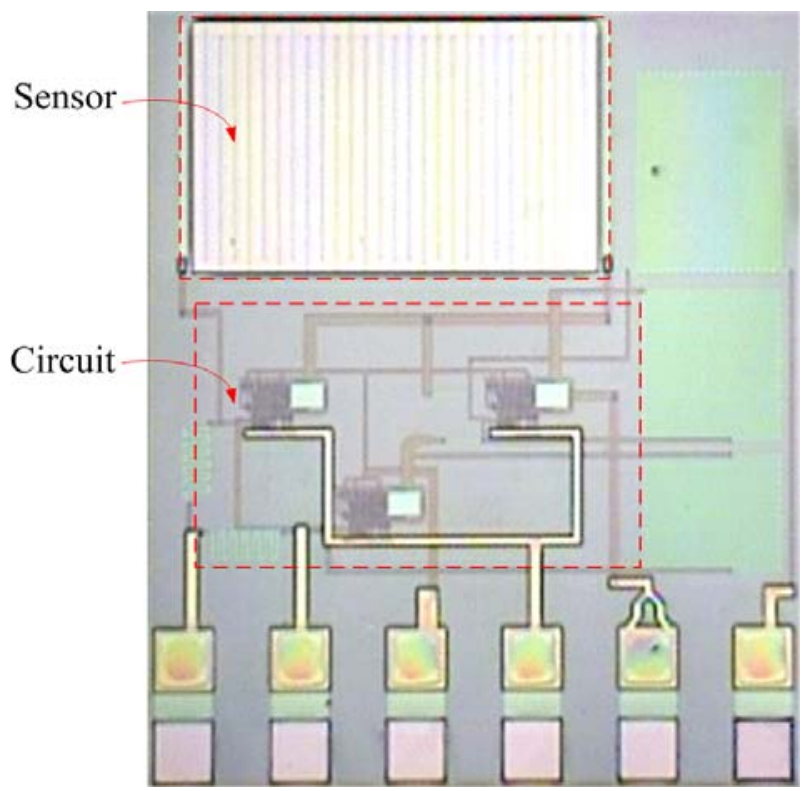


In the $\mathrm{CO}$ sensor, the sacrificial layers were the metal and via layers. The materials of the via and metal layers were tungsten (W) and aluminum (Al), respectively. The sacrificial layers have to be removed from the sensor chip, exposing the polysilicon resistor. As shown in Figure 8(b), the sensor chip was immersed in two etchants: one was an Al etchant with phosphoric acid, nitric acid, acetic acid and deionized water in a ratio of 14:1:2:3. The other was a $\mathrm{W}$ etchant with sulfuric acid and hydrogen peroxide in a ratio of 2:1. Figure 10 depicts a SEM image of the CO sensor after the wet etching process. Then, the sensor chip was put in an oven at $300^{\circ} \mathrm{C}$ for $8 \mathrm{~h}$, so that a thin silicon dioxide layer was formed on the surface of polysilicon resistor. Finally, as shown in Figure 8(c), the cobalt oxide film was coated on the polysilicon resistor.

Figure 10. SEM image of the $\mathrm{CO}$ sensor after the wet etching process.

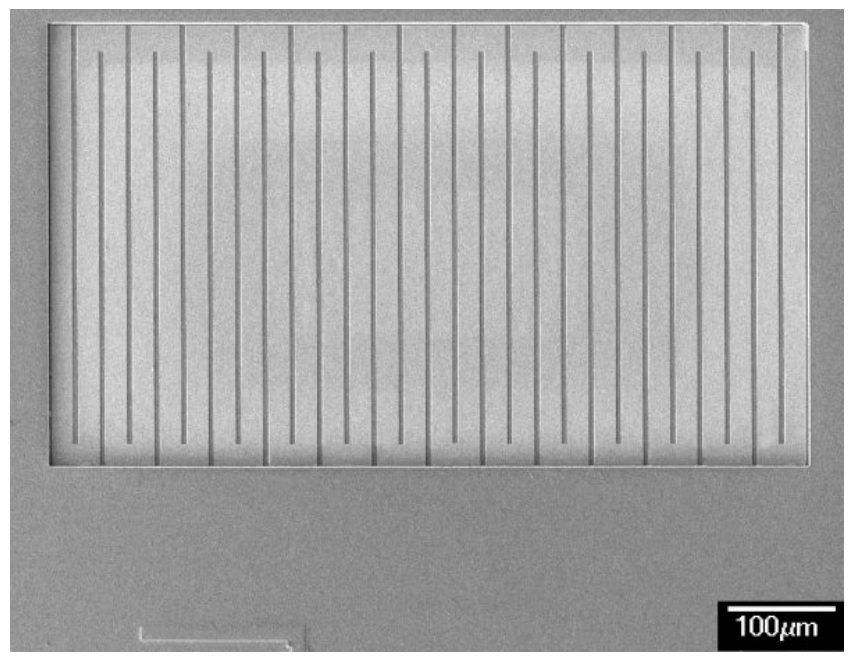

\section{Results and Discussion}

The characteristic of the CO sensor chip was measured using a test chamber, a power supply, an LCR meter and an oscilloscope. In order to characterize the variation of resistance in the sensing part, the $\mathrm{CO}$ sensor was tested without the readout circuit. The CO sensor chip without readout circuit was set in the test chamber, and the LCR meter was employed to measure its resistance variation at room temperature at different $\mathrm{CO}$ concentrations. Figure 11 shows the results. The initial resistance of the $\mathrm{CO}$ sensor was about $20 \mathrm{k} \Omega$ (in air), and the resistance of the sensor varied to $21.1 \mathrm{k} \Omega$ at $200 \mathrm{ppm} \mathrm{CO}$. The results revealed that the resistance of the $\mathrm{CO}$ sensor increased as the concentration of $\mathrm{CO}$ increased. The response time represented the reaction time of $90 \%$ from the initial resistance to the stable resistance, and the recovery time was the return time of $90 \%$ from the stable resistance to the initial resistance. As shown in Figure 11, the CO sensor had a response time of about $23 \mathrm{~s}$ at $200 \mathrm{ppm}$ $\mathrm{CO}$ and a recovery time of $35 \mathrm{~s}$ at $200 \mathrm{ppm} \mathrm{CO}$.

The CO sensor with readout circuit was set in the test chamber and was tested at room temperature with different $\mathrm{CO}$ concentrations. The power supply provided a bias voltage of $3.3 \mathrm{~V}$ and an input voltage of $3 \mathrm{~V}$ to the readout circuit in the sensor. The oscilloscope was utilized to measure the output voltage of the sensor at room temperature at different $\mathrm{CO}$ concentrations. Figure 12 depicts the measured results of output voltage for the $\mathrm{CO}$ sensor with readout circuit. In this measurement, the $\mathrm{CO}$ 
gas was provided from 0 to $200 \mathrm{ppm}$. The results showed that the output voltage of the CO sensor changed from 826 to $863 \mathrm{mV}$ as the concentration of $\mathrm{CO}$ gas varied from 0 to $200 \mathrm{ppm}$. The variation of the output voltage was $37 \mathrm{mV}$ in $0-200 \mathrm{ppm} \mathrm{CO}$. Therefore, the integrated $\mathrm{CO}$ sensor had a sensitivity of $0.19 \mathrm{mV} / \mathrm{ppm}$ when providing a bias voltage of $3.3 \mathrm{~V}$ and an input voltage of $3 \mathrm{~V}$.

Figure 11. Relation between the resistance variation and $\mathrm{CO}$ concentration for the $\mathrm{CO}$ sensor.

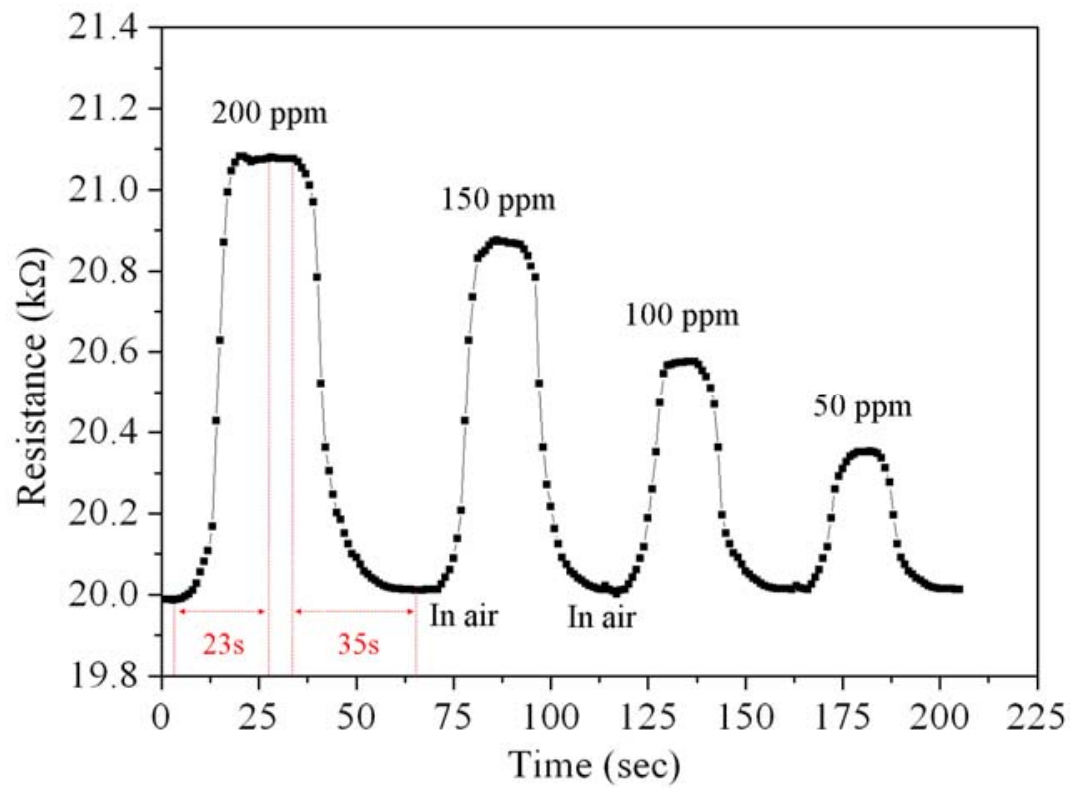

Figure 12. Measured results of the output voltage for the $\mathrm{CO}$ sensors.

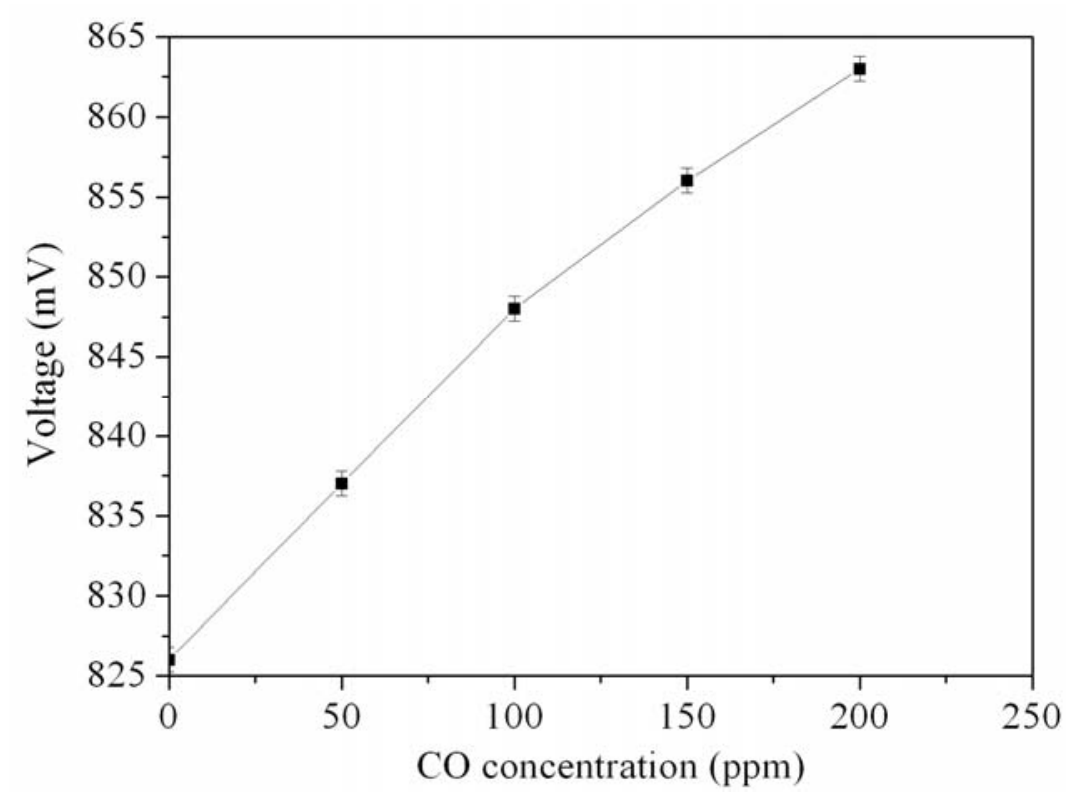

The carbon monoxide sensors, proposed by Tabata et al. [9], Chan et al. [10], Barrettino et al. [11] and Briand et al. [12], needed micro hotplates or micro heaters to provide a high working temperature for the gas sensing films, leading to increased power consumption of the sensors. In this study, the $\mathrm{CO}$ sensor did not require a micro heater and could work at room temperature. These sensors [9-12] also did not have integrated circuits-on-a-chip, so they needed to use packaging to combine with circuits. In 
this work, the CO sensor was integrated with a readout circuit-on-a-chip using the CMOS-MEMS technique, so that the production cost was reduced. The experimental results showed that the readout circuit could operate normally after the post-process, indicat8ing that the post-process used was compatible with the commercial CMOS process.

\section{Conclusions}

A micro carbon monoxide sensor integrated with a readout circuit-on-a-chip has successfully been implemented using a commercial CMOS process and a post-process. The sensor was constructed with a polysilicon resistor and a sensing film. The sensing film of the sensor was a composite film of a cobalt oxide nanosheet and carbon nanotubes. The sensor required a post-process to coat the sensing film. The post-process utilized etchants to etch the sacrificial layers to expose the polysilicon resistor, and then the sensing film was coated on the polysilicon resistor. The advantage of the post-process was that it is compatible with the CMOS process. The sensor was a resistive type, and its resistance generated a change when the sensing film absorbed or desorbed $\mathrm{CO}$ gas. The resistance variation of the gas sensor was converted by the readout circuit into the output voltage. The experimental results showed that the sensitivity of the $\mathrm{CO}$ gas sensor was about $0.19 \mathrm{mV} / \mathrm{ppm}$ at room temperature, and the response and recovery times were $23 \mathrm{~s}$ and $35 \mathrm{~s}$ at $200 \mathrm{ppm} \mathrm{CO}$, respectively.

\section{Acknowledgements}

The authors would like to thank National Center for High-performance Computing (NCHC) for chip simulation, National Chip Implementation Center (CIC) for chip fabrication and the National Science Council of the Republic of China for financially supporting this research under Contract No NSC 982221-E-005-070.

\section{References}

1. Esfandyarpour, B.; Mohajerzadeh, S.; Famini, S.; Khodadadi, A.; Asl Soleimani, E. High sensitivity Pt-doped $\mathrm{SnO} 2$ gas sensors fabricated using sol-gel solution on micromachined $\left(\begin{array}{lll}1 & 0 & 0\end{array}\right)$ Si substrates. Sens. Actuat. B 2004, 100, 190-194.

2. Yoon, D.H.; Choi, G.M. Microstructure and Co gas sensing properties of porous ZnO produced by starch addition. Sens. Actuat. B 1997, 45, 251-257.

3. Choi, J.D.; Choi, G.M. Electrical and $\mathrm{CO}$ gas sensing properties of layered $\mathrm{ZnO}-\mathrm{CuO}$ sensor. Sens. Actuat. B 2000, 69, 120-126.

4. Korotcenkov, G.; Brinzari, V.; Gemeavschi, A.; Ivanov, M.; Comet, A. In203 films deposited by spray pyrolysis: gas response to reducing (CO, H2) gases. Sens. Actuat. B 2004, 98, 122-129.

5. Khatko, V.; Llobet, E.; Vilanova, X.; Brezmes, J.; Hubalek, J.; Malysz K.; Correig, X. Gas sensing properties of nanoparticle indium-doped WO3 thick films. Sens. Actuat. B 2005, 111-112, 45-51. 
6. Geng, B., Zhan, F.; Fang, C.; Yu, N. A facile coordination compound precursor route to controlled synthesis of $\mathrm{Co}_{3} \mathrm{O}_{4}$ nanostructures and their room-temperature gas sensing properties. J. Mater. Chem. 2008, 18, 4977-4984.

7. Wu, R.J.; Chang, W.C.; Tsai, K.M.; Wu, J.G. The novel CO sensing material CoOOH-WO3 with Au and SWCNT performance enhancement. Sens. Actuat. B 2009, 138, 35-41.

8. Madou, M.J. Fundamentals of Microfabrication; CRC Press: Boca Raton, FL, USA, 2002.

9. Tabata, S.; Higaki, K.; Ohnishi, H.; Suzuki, T.; Kunihara, K.; Kobayashi, M. A micromachined gas sensor based on a catalytic thick film/SnO2 thin film bilayer and a thin film heater: Part 2: CO sensing. Sens. Actuat. B 2005, 109, 190-193.

10. Chan, P.C.H.; Yan, G.Z.; Sheng, L.Y.; Sharma, R.K.; Tang, Z.; Sin, J.K.O.; Hsing, I.M.; Wang, Y. An integrated gas sensor technology using surface micro-machining. Sens. Actuat. B 2002, 82, 277-283.

11. Barrettino, D.; Graf, M.; Song, W.H.; Kirstein, K.U.; Hierlemann, A.; Baltes, H. Hotplate-based monolithic CMOS microsystems for gas detection and material characterization for operating temperatures up to 500C. IEEE J. Solid State Circuits 2004, 39, 1202-1207.

12. Briand, D.; Krauss, A.; Van Der Schoot, B.; Weimar, U.; Barsan, N.; Göpel, W.; De Rooij, N.F. Design and fabrication of high-temperature micro-hotplates for drop-coated gas sensors. Sens. Actuat. B 2000, 68, 223-233.

13. Cogdell, J.R. Foundation of Electronics; Prentice Hall: Bergen County, NJ, USA, 1999.

14. Fedder, G.K.; Howe, R.T.; Liu, T.J.K.; Quévy, E.P. Technologies for cofabricating MEMS and electronics. Proc. IEEE 2008, 96, 306-322.

15. Kao, P.H.; Dai, C.L.; Hsu, C.C.; Lee, C.Y. Fabrication and characterization of a tunable in-plane resonator with low driving voltage. Sensors 2009, 9, 2062-2075.

16. Dai, C.L.; Lu, P.W.; Wu, C.C.; Chang, C. Fabrication of wireless micro pressure sensor using the CMOS process. Sensors 2009, 9, 8748-8760.

17. Liu, M.C.; Dai, C.L.; Chan, C.H.; Wu C.C. Manufacture of a polyaniline nanofiber ammonia sensor integrated with a readout circuit using the CMOS-MEMS technique. Sensors 2009, 9, 869-880.

18. Kao, P.H.; Dai, C.L.; Hsu, C.C.; Lee, C.Y. Manufacture of micromirror array using CMOSMEMS technique. Sensors 2009, 9, 6219-6231.

19. Wu, R.J.; Wu, J.G.; Tsai, T.K.; Yeh, C.T. Use of cobalt oxide $\mathrm{CoOOH}$ in a carbon monoxide sensor operating at low temperatures. Sens. Actuat. B 2006, 120, 104-109.

20. Zhuiyakov, S. Carbon monoxide detection at low temperature by semiconductor sensor with nanostructured Au-doped CoOOH films. Sens. Actuat. B 2008, 129, 431-441.

21. Dai, C.L.; Liu, M.C.; Chen, F.S.; Wu, C.C.; Chang, M.W. A nanowire $\mathrm{WO}_{3}$ humidity sensor integrated with micro heater and inverting amplifier circuit on chip manufactured using CMOSMEMS technique. Sens. Actuat. B 2007, 123, 896-901.

(C) 2010 by the authors; licensee Molecular Diversity Preservation International, Basel, Switzerland. This article is an open-access article distributed under the terms and conditions of the Creative Commons Attribution license (http://creativecommons.org/licenses/by/3.0/). 